\title{
Psychometric Properties of the Stress Mindset Measure (SMM) in a Greek Sample
}

\section{Konstantinos Karampas, Christos Pezirkianidis, Anastassios Stalikas}

Laboratory of Positive Psychology, Department of Psychology, Panteion University of Social and Political Sciences, Athens, Greece

Email: karabaskonstantinos@gmail.com

How to cite this paper: Karampas, K., Pezirkianidis, C., \& Stalikas, A. (2020). Psychometric Properties of the Stress Mindset Measure (SMM) in a Greek Sample. Psychology, 11, 1185-1199.

https://doi.org/10.4236/psych.2020.118079

Received: July 27, 2020

Accepted: August 24, 2020

Published: August 27, 2020

Copyright $\odot 2020$ by author(s) and Scientific Research Publishing Inc. This work is licensed under the Creative Commons Attribution International License (CC BY 4.0).

http://creativecommons.org/licenses/by/4.0/ (c) (i) Open Access

\begin{abstract}
The aim of this study is to evaluate the psychometric properties of the Stress Mindset Measure (SMM) in a non-clinical sample of the Greek population. The Stress Mindset Measure (SMM) is an 8-item instrument, designed to assess the extent to which an individual believes that the effects of stress are either enhancing or debilitating. The validation was carried out in a sample of 784 Greek adults, aging from 18 to 65 years old. Results indicated that the Greek version of the Stress Mindset Measure (SMM) has satisfactory reliability and validity indexes. Moreover, the findings showed that having a positive stress mindset is positively correlated to positive wellbeing indices and positive ways of perceiving and coping with stress. Also, having a positive stress mindset is negatively correlated to negative experiences and with less effective ways of coping with stress. On the other hand, having a negative stress mindset is negatively correlated to positive wellbeing outputs and effective coping mechanisms and also positively correlated with psychological symptomatology and negative feelings. The results of this study suggest that the Greek SMM can be used as a reliable and valid instrument for the measurement of stress mindset in the Greek population.
\end{abstract}

\section{Keywords}

Stress Mindset Measure (SMM), Greek Validation, Reliability, Validity, Psychometric Properties

\section{Introduction}

Stress mindset is conceptualized as one's belief that stress has either enhancing or debilitating consequences for outcomes such as health, performance, and well-being (Crum, Salovey, \& Achor, 2013). Research suggests that "stress-is-enhancing" and 
"stress-is-debilitating" mindsets can differentially affect physiological and behavioral responses under stress (Crum et al., 2013). More specifically, individuals with a positive stress mindset tend to approach stressful situations in order to achieve enhancing outcomes (Crum et al., 2013; Casper, Sonnentag, \& Tremmel, 2017). In contrast, individuals with a negative stress mindset are less likely to approach stressful situations in order to avoid potential negative consequences (e.g., impaired well-being; Crum et al., 2013). Moreover, the extent to which individuals believe that stress is debilitating has in itself been positively associated with morbidity (Nabi, Kivimäki, Batty, Shipley, Britton, Brunner, \& Singh-Manoux, 2013) and mortality rates (Keller, Litzelman, Wisk, Maddox, Cheng, Creswell, \& Witt, 2012). On the other hand, stress may also produce favorable outcomes (for reviews see: Podsakoff, LePine, \& LePine, 2007; Updegraff \& Taylor, 2000), as research suggests that a "stress-is-enhancing" mindset, over and above the effects of stress level, seems to improve self-reported health and work performance (Crum et al., 2013), as well as to enhance physiological functioning and performance (e.g., Jamieson, Mendes, Blackstock, \& Schmader, 2010; Jamieson, Mendes, \& Nock, 2013). Furthermore, research indicates that stress mindset can be changed to improve stress responses (Crum et al., 2013; Crum, Akinola, Martin, \& Fath, 2017).

The Stress Mindset Measure (SMM; Crum et al., 2013) is a self-report 8-item instrument, designed to assess the extent to which an individual believes that the effects of stress are either enhancing or debilitating. The original validation study of the SMM (Crum et al., 2013), demonstrated that stress mindset is a distinct variable from traditional stress-influencing variables (amount, appraisal, and coping) and that stress mindset is meaningfully related to stress-relevant outcomes (health, performance, and well-being). Moreover, the SMM was found to positively correlate with measures related to stress, including hardiness and optimism and to discriminate from similar concepts, such as perceived stress, optimism (appraisal), approach coping and avoidance coping (Crum et al., 2013). Further, it was found that "stress-is-enhancing" mindset was positively correlated with life satisfaction and with fewer symptoms of depression and anxiety, over and above the levels of stress, active coping, social coping, distractive coping, and avoidance coping (Crum et al., 2013).

In the validation study of the SMM (Crum et al., 2013), two versions of the measure were created: One referring to beliefs about the nature of stress in general (SMM-G) and one referring to beliefs about the nature of stress in the context of a specific stressor (SMM-S). Results have shown high internal consistency for both versions of the SMM (Cronbach's alpha was 0.80 for the SMM-S and 0.86 for the SMM-G). Age and sex were both unrelated to SMM scores. The SMM-G and the SMM-S were significantly correlated with one another, $r$ (335) $=0.61, p=0.001$. Confirmatory factor analyses confirmed a simple structure of the SMM, suggesting that it is appropriately described as unifactorial (Crum et al., 2013). However, the psychometric properties of the Greek SMM have yet to 
be validated.

The aim of the present study is, first to translate and adapt the Stress Mindset Measure (SMM) in a Greek sample, and second to examine the validity, reliability and factorial invariance of the instrument using a number of mental health and well-being measures. Thus, the present study will focus on answering the following research questions: 1) Could SMM be efficiently adapted in the Greek context? 2) Is the Greek version of SMM a valid and reliable instrument for the measurement of stress mindset? 3) Does the Greek version of SMM demonstrate the same structure across gender?

\section{Method}

\subsection{Translation and Adaptation into the Greek Cultural Context}

Following the permission by Stress Mindset Measure (SMM) creator, Professor Alia Crum, to adapt the questionnaire in Greek, we followed a six-step methodology for the translation and adaptation of the SMM (Pezirkianidis, Karakasidou, Dimitriadou, \& Stalikas, 2017), as described below.

Independent Forward Translation. Three translators that fluently speak English and have a background on psychology and psychological testing independently translated the original version of the questionnaire from English to Greek.

Forward Translation Verification (Committee Approach). The same three translators with the main examiner compared the three different versions of the Greek translation for each item and, after comparing it with the original version, finalized the first version of the SMM.

Independent Backward Translation. A different set of three bilingual translators reached consensus in finalizing the wording and translated independently the Greek version of the questionnaire back to English.

Backward Translation Verification (Committee Approach). The same three translators with the main examiner compared the three versions of the back-translated questionnaire and reached consensus on the final back-translated version.

Final Verification by an Expert. Isaac Handley-Miner, Mind \& Body Lab Manager, Department of Psychology, Stanford University, compared the original version of the questionnaire with its back-translated version and suggested if there are any differences in the item level in meaning and construct coherence. Based on his suggestions, the necessary corrections were made in the Greek version of the instrument.

Pilot Testing. The last step of the adaptation in the Greek cultural context was to conduct a small-range study to test the way participants respond to the items of the questionnaire. The Greek version of the instrument was administered to 40 Greek adults of different gender and age groups, who speak English fluently (convenience sample). After two weeks, the same participants completed the original version of the questionnaire. Their responses were analyzed using the SPSS 25 (Table 1). 
Table 1. Paired samples correlations of the SMM items for the original and the Greek version.

\begin{tabular}{cccc}
\hline Item No. & $N$ & $r_{p}$ & $p$ value \\
\hline 1 & 40 & 0.778 & 0.000 \\
2 & 40 & 0.674 & 0.000 \\
3 & 40 & 0.785 & 0.000 \\
4 & 40 & 0.838 & 0.000 \\
5 & 40 & 0.588 & 0.000 \\
6 & 40 & 0.453 & 0.003 \\
7 & 40 & 0.838 & 0.000 \\
8 & 40 & 0.608 & 0.000 \\
\hline
\end{tabular}

\subsection{Participants}

The sample of the study consisted of 784 Greek adults $(29.2 \%$ men, $70.8 \%$ women), aging from 18 to 65 years old (Mage $=33.95$ ). The majority of our sample was employed ( $81.5 \%$ employed, $18.5 \%$ unemployed). Regarding the marital status of the respondents, $33.2 \%$ of them were married, $58.3 \%$ were unmarried, $6.9 \%$ were divorced and $1.7 \%$ were widowers.

\subsection{Measures}

In the present study, in addition to the Stress Mindset Measure (SMM) and demographics, we used six instruments to establish convergent and discriminant validity of the Greek version of Stress Mindset Measure (SMM), as followed:

Demographics. Participants were asked to report demographic information regarding their gender, age, marital and employment status.

1) Stress Mindset Measure (SMM; Crum, Salovey, \& Achor, 2013). In the SMM the participants are rating how strongly they agree or disagree with eight statements (e.g., the effects of stress are positive and should be utilized, the effects of stress are negative and should be avoided) on a 0 (strongly disagree) to 4 (strongly agree) scale with numbers equal to or above two reflecting a stress-is-enhancing mindset.

2) Satisfaction With Life Scale (SWLS; Diener, Emmons, Larsen, \& Griffin, 1985; Greek version: Galanakis, Lakioti, Pezirkianidis, Karakasidou, \& Stalikas, 2017). The scale measures individual's cognitive assessment of his/her life indicating satisfaction with life levels. The SWLS consists of five items rated on a 7-point Likert-type scale (1-Strongly disagree to 7-Strongly agree). In the present study the scale demonstrated adequate internal consistency levels $(\alpha=0.88)$.

3) Depression Anxiety Stress Scales-9 (DASS-9; Yusoff, 2013; Greek version: Kyriazos, Stalikas, Prassa, \& Yotsidi, 2018b). DASS-9 is an empirically derived version based on DASS-21 (Lovibond \& Lovibond, 1995; Pezirkianidis, Karakasidou, Lakioti, Stalikas, \& Galanakis, 2018). The DASS-9 measures three negative emotional states a) depression, b) anxiety, and c) tension/stress. Respondents 
report the presence of 9 symptoms over the previous week using a Likert-type scale (0-Did not apply to me at all to 3-Applied to me very much or most of the time). In the present study, the scales demonstrated marginal internal consistency levels ( $\alpha=0.69, \alpha=0.77, \& \alpha=0.66$, respectively).

4) Perceived Stress Scale (PSS; Cohen, Kamarck, \& Mermelstein, 1983; Greek version: Andreou, Alexopoulos, Lionis, Varvogli, Gnardellis, Chrousos et al., 2011). The Perceived Stress Scale (PSS) has been developed to measure general stress (Cohen, Kamarck, \& Mermelstein, 1983) based on the conceptualization of stress as an appraisal of something threatening and that people cope with stress more or less effectively (Lazarus \& Folkman, 1984). PSS is a self-report scale with both negative items (expressing stress) and positive items (expressing coping capacity). The Greek versions of the PSS-14 and PSS-10 exhibited satisfactory psychometric properties and their use for research is warranted (Andreou et al., 2011). PSS items ask participants to reflect on the past month and include questions such as "Have you been upset by something that happened unexpectedly?" and "Have you felt that you could not cope with all the things you had to do?" (Scale: $0=$ never to $4=$ very often). In the present study the scale demonstrated adequate internal consistency levels $(\alpha=0.87)$.

5) Brief-COPE inventory (Carver, 1997; Greek version: Kapsou, Panayiotou, Kokkinos, \& Demetriou, 2010). The Brief-COPE is a 28 -item measure of strategies used by individuals to cope with problems and stress. The items answered on a four-point Likert-type scale ranging from $1=$ "not at all" to 4 = "very much". The Greek version of the Brief-COPE inventory revealed a structure comprised of eight factors, four of which were broader, and included active/positive, avoidant, support seeking and negative emotional approaches (Kapsou et al., 2010). In the present study the five subscales demonstrated adequate internal consistency levels ( $\alpha=0.71$ to 0.90 ), while three subscales demonstrated inadequate internal consistency levels and their results should be interpreted with caution, namely humor $(\alpha=0.50)$, avoidance $(\alpha=0.54)$, and expression of negative feelings ( $\alpha=0.42)$.

6) Brief Resilience Scale (BRS; Smith, Dalen, Wiggins, Tooley, Christopher, \& Bernard, 2008; Greek version: Kyriazos, Stalikas, Prassa, Galanakis, Yotsidi, \& Lakioti, 2018a) is a brief measure of resilience. It contains 6 items measuring the ability to bounce back from stress and difficulties (e.g., "I usually come through difficult times with little trouble"). The items are rated on a 5-point Likert scale from 1 (Strongly Disagree) to 5 (Strongly Agree). Possible score ranges from 1 (minimum resilience) to 6 (maximum resilience). Three items are negatively worded and are reversed scored. In the present study the scale demonstrated adequate internal consistency levels $(\alpha=0.82)$.

7) Scale of Positive and Negative Experience 8 (SPANE; Diener, Wirtz, Tov, Kim-Prieto, Choi, Oishi et al., 2010; Greek version SPANE 8: Kyriazos, Stalikas, Prassa, \& Yotsidi, 2018c). SPANE-8 (Kyriazos et al., 2018c) is a revised structure containing one general feeling per dimension instead of three in the original SPANE (Diener et al., 2010). This resulted in a briefer structure with four posi- 
tive (Pleasant, Happy, Joyful, Contented) and four negative (Bad, Sad, Afraid, Angry) items. Items are scored on a Likert scale from 1 (very rarely or never) to 5 (very often or always). In the present study the subscales demonstrated adequate internal consistency levels ( $\alpha=0.88$ and $\alpha=0.80$, respectively).

\section{Results}

\subsection{Translation and Pilot Testing}

Paired samples correlations of the Stress Mindset Measure (SMM) items for the original and the Greek version were computed, as depicted in Table 1. The results show that the correlations between the two versions of the items are high and statistically significant. The final Greek version of the Stress Mindset Measure (SMM) is presented in Table 2.

\subsection{Inter-Item Correlations}

First, the correlations among the eight (8) SMM items were tested and values between 0.20 and 0.40 (see Table 3 ) would be considered to indicate reasonable item homogeneity. However, correlations greater than 0.40 would indicate that the items do not capture a big width of the factor variance (Piedmont, 2014). After reversing the negative items, the findings indicated that the inter-item correlations ranged from 0.18 to 51 indicating that there is reasonable item homogeneity. In other words, SMM items appear to measure the same concept.

\subsection{Confirmatory Factor Analysis}

To test the construct validity of the measure we conducted two confirmatory factor analyses (CFA) using the IBM SPSS AMOS, version 22 (Byrne, 2013). Based on the suggested model created by Crum and colleagues (2013), we created a first-order single-factor model, in which all the eight items loaded on a single stress mindset factor. Also, based on the two elements of the suggested model, we tested a first-order two-factor model, in which four items (q2, q4, q6,

Table 2. List of the SMM items in the original and the Greek version.

\begin{tabular}{|c|c|c|}
\hline $\begin{array}{l}\text { Item } \\
\text { No. }\end{array}$ & Original version & Greek version \\
\hline 1 & The effects of stress are negative and should be avoided. & 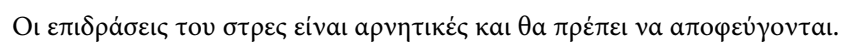 \\
\hline 2 & Experiencing stress facilitates my learning and growth. & 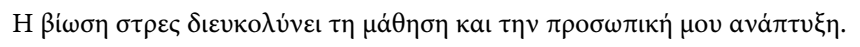 \\
\hline 3 & Experiencing stress depletes my health and vitality. & 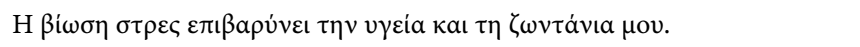 \\
\hline 4 & $\begin{array}{l}\text { Experiencing stress enhances my performance } \\
\text { and productivity. }\end{array}$ & 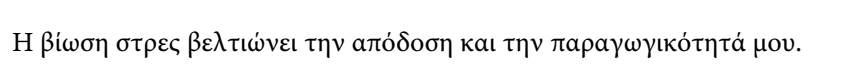 \\
\hline 5 & Experiencing stress inhibits my learning and growth. & 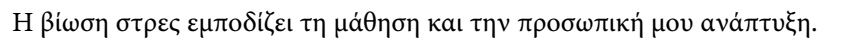 \\
\hline 6 & Experiencing stress improves my health and vitality. & 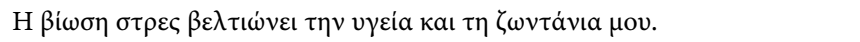 \\
\hline 7 & $\begin{array}{l}\text { Experiencing stress debilitates my performance } \\
\text { and productivity. }\end{array}$ & 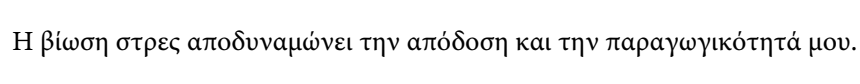 \\
\hline 8 & The effects of stress are positive and should be utilized. & 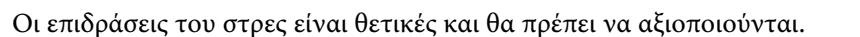 \\
\hline
\end{tabular}


Table 3. Stress Mindset Measure inter-item correlations $(N=784)$.

\begin{tabular}{ccccccccc}
\hline Item No. & $\mathbf{1}$ & $\mathbf{2}$ & $\mathbf{3}$ & $\mathbf{4}$ & $\mathbf{5}$ & $\mathbf{6}$ & $\mathbf{7}$ & $\mathbf{8}$ \\
\hline 1 & 1 & & & & & & & \\
2 & 0.43 & 1 & & & & & & \\
3 & 0.39 & 0.46 & 1 & & & & & \\
4 & 0.37 & 0.40 & 0.51 & 1 & & & & \\
5 & 0.23 & 0.24 & 0.41 & 0.33 & 1 & & & \\
6 & 0.25 & 0.21 & 0.33 & 0.32 & 0.44 & 1 & & \\
7 & 0.19 & 0.32 & 0.22 & 0.18 & 0.35 & 0.44 & 1 & \\
8 & 0.38 & 0.34 & 0.41 & 0.37 & 0.44 & 0.42 & 0.40 & 1 \\
\hline
\end{tabular}

Note. Every correlation is significant at $p$-value $<0.001$. Items $1,3,5$, and 7 have been reversed.

q8) loaded on a factor that capture the mindset about the enhancing effects of stress, while four items (q1, q3, q5, q7) loaded on a factor that measures the mindset regarding the debilitating effects of stress.

To assess overall model fit, we evaluated different goodness of fit indices based on the cutoff criteria suggested by $\mathrm{Hu}$ and Bentler (1999). The $\chi^{2}$ ratio ( $\chi 2 /$ degrees of freedom) was used and values less than 3 would indicate good model fit (Kline, 2010). Moreover, the standardized root mean-square residual (SRMR; Hu \& Bentler, 1995), the comparative fit index (CFI; Bentler, 1990), the goodness of fit index (GFI; Joreskog \& Sorbom, 1984), the Tucker-Lewis index (TLI; Tucker \& Lewis, 1973), and the expected cross-validation index (ECVI; Schreiber, Nora, Stage, Barlow, \& King, 2006) were evaluated. According to $\mathrm{Hu}$ and Bentler (1999), SRMR values below 0.08 indicate good model fit. Moreover, CFI, TLI and GFI values greater than 0.90 are indicative of acceptable model fit and values higher than 0.95 show great model fit. Also, when comparing two models, smaller ECVI values indicate better model fit.

The results showed that for both models, $\mathrm{x} 2$ ratio was higher than 3 , due to the big sample size (Schermelleh-Engel, Moosbrugger, \& Müller, 2003), however, regarding the single-factor model, CFI and TLI values were unacceptable $(<$ $0.90)$, while SRMR and GFI values were acceptable $(<0.08$ and $>0.90$, respectively). The fit indices for the two-factor model were found to be surprisingly better than the single factor model.

More specifically, CFI, TLI, and GFI values were higher than 0.90, SRMR value was less than 0.08 , and ECVI value was smaller than the first model indicating better model fit (see Table 4 and Figure 1).

\subsection{Internal Consistency Reliability}

We evaluated the internal consistency reliability of the two factors and total score of the SMM using the Cronbach's alpha coefficient. The results showed alpha values higher than 0.70 both for the two factors $(\alpha=0.74$ for the positive and 0.75 for the negative factor) and the total score $(\alpha=0.071)$ indicating acceptable internal consistency (DeVellis, 2012; Kyriazos, 2017). 


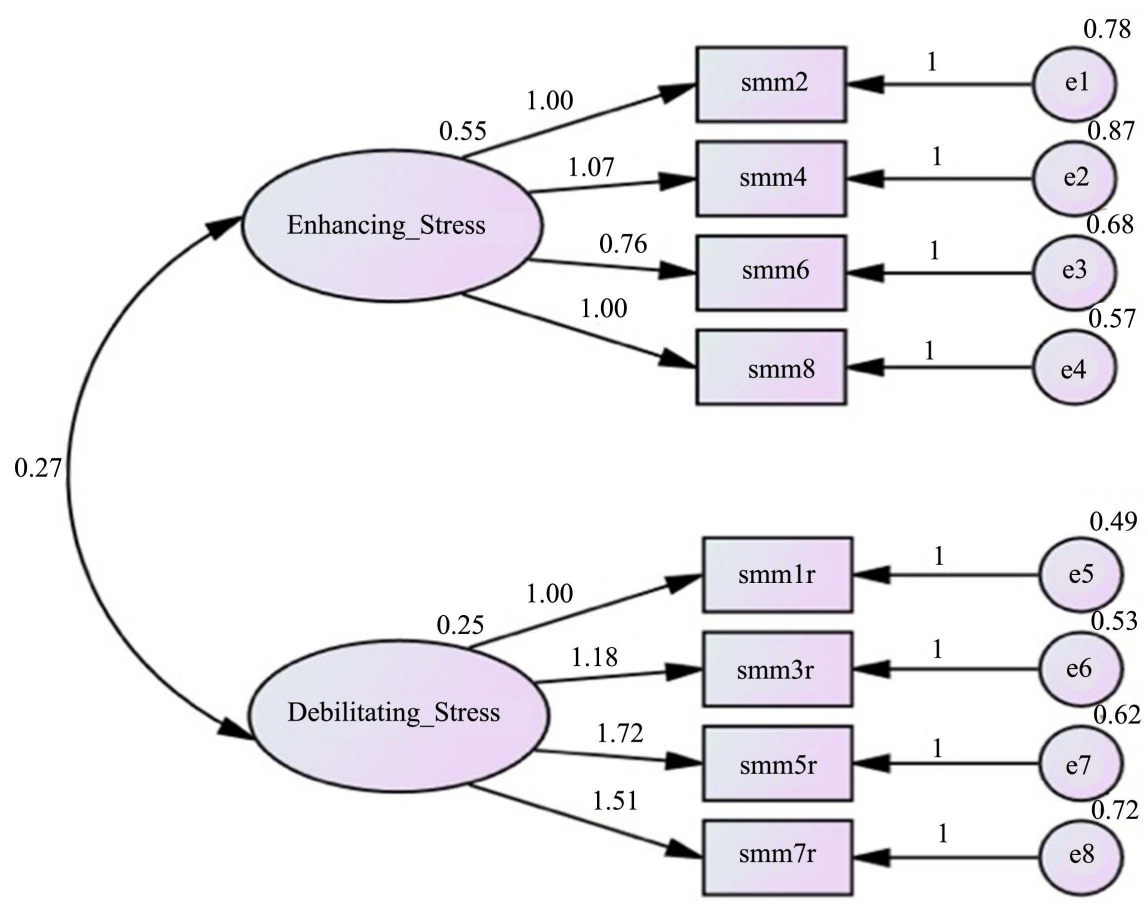

Figure 1. The two-factor solution model for the Greek version of the Stress Mindset Measure.

Table 4. Fit indices in confirmatory factor analysis for a single-factor and a two-factor model of the Stress Mindset Measure.

\begin{tabular}{cccccccccc}
\hline Model & $\chi^{2}$ & $\chi^{2} p$ & $d f$ & $\chi^{2} / d f$ & $C F I$ & $T L I$ & $S R M R$ & GFI & ECVI \\
\hline 1) factor & 254.454 & 0.000 & 20 & 12.723 & 0.858 & 0.802 & 0.066 & 0.917 & 0.366 \\
2) factors & 116.595 & 0.000 & 19 & 6.137 & 0.941 & 0.913 & 0.041 & 0.965 & 0.192 \\
\hline
\end{tabular}

Note. Extraction method: maximum likelihood. Items 1, 3, 5, and 7 have been reversed to insert them in both models in the same way.

\subsection{Convergent and Discriminant Validity}

The correlations between SMM factors, and positive or negative constructs relevant to experiencing and coping stress were examined to test measure's convergent and discriminant validity (see Table 5 ). The findings showed that having an enhancing stress mindset and believing in the enhancing effects of stress is positively correlated to positive wellbeing indices (higher levels of resilience and experiencing of positive emotions) and ways of perceiving stress (self-efficacy when confronting stress) and coping with it (e.g. humor and spirituality). Also, having an enhancing stress mindset is negatively correlated to negative experiences, like experiencing negative emotions and feeling helpless when confronting with stress, and less effective ways of coping with stress, like expressing negative feelings.

On the other hand, the results indicated that having a debilitating stress mindset and focusing on the debilitating effects of stress is negatively correlated to positive wellbeing indices (lower levels of satisfaction with life, positive 
Table 5. Convergent and discriminant validity: Average correlations of SMM factors with positive and negative constructs relevant to perceiving, experiencing and confronting stress $(N=784)$.

\begin{tabular}{|c|c|c|}
\hline & Positive SM & Negative SM \\
\hline Positive Stress Mindset & 1 & \\
\hline Negative Stress Mindset & $-0.53^{* * *}$ & 1 \\
\hline Satisfaction With Life (SWLS) & 0.06 & $-0.10^{\star *}$ \\
\hline Depression (DASS-9) & -0.05 & $0.20^{* * *}$ \\
\hline Anxiety (DASS-9) & -0.03 & $0.15^{* * *}$ \\
\hline Stress (DASS-9) & -0.05 & $0.18^{* * *}$ \\
\hline Resilience (BRS) & $0.15^{\star * *}$ & $-0.19^{* * *}$ \\
\hline Positive Emotions (SPANE-8) & $0.09^{*}$ & $-0.16^{\star * *}$ \\
\hline Negative Emotions (SPANE-8) & $-0.09^{*}$ & $0.21^{* * *}$ \\
\hline Perceived Stress (PSS) & $-0.11^{* *}$ & $0.21^{\star * *}$ \\
\hline Perceived Helplessness (PSS) & $-0.09^{* *}$ & $0.24^{* * *}$ \\
\hline Self-efficacy (PSS) & $0.09^{* *}$ & $-0.11^{* *}$ \\
\hline Active/Positive Coping (COPE) & -0.02 & 0.00 \\
\hline Behavioral Disengagement (COPE) & 0.06 & $0.08^{*}$ \\
\hline Avoidance (COPE) & -0.05 & $0.19^{* * *}$ \\
\hline Substance Use (COPE) & 0.02 & 0.01 \\
\hline Religion (COPE) & $0.09^{*}$ & 0.00 \\
\hline Seeking Support (COPE) & -0.06 & 0.03 \\
\hline Humor (COPE) & $0.12^{* *}$ & $-0.13^{\star * *}$ \\
\hline Expression of Negative Feelings (COPE) & -0.05 & $0.16^{* * *}$ \\
\hline
\end{tabular}

Note. $\mathrm{SM}=$ Stress Mindset. ${ }^{* *} p<0.001,{ }^{* *} p<0.010,{ }^{*} p<0.050$.

emotions, resilience and self-efficacy when confronting stress) and effective coping mechanisms, like using humor. Moreover, being characterized by a debilitating stress mindset is positively correlated with psychological symptomatology (high levels of depression, anxiety and stress), negative feelings (perceived helplessness when confronting stress and negative emotions), and ineffective ways of coping with stress, e.g. avoidance, behavioral disengagement, and expression of negative feelings. These findings indicate that the Greek version of the Stress Mindset Measure has high convergent and discriminant validity, since there are positive correlations of the factors with similar constructs (convergent validity) and negative or non-correlations with conceptually antithetical constructs (discriminant validity; Hubley, 2014).

\subsection{Factorial Invariance}

We tested the factorial invariance across gender of the SMM two-factor model created in AMOS. Concerning the existence of configural invariance, the results 
show that the data fit adequately to the model without any cross-groups constrains. More specifically, the fit indices indicate acceptable model fit, since CFI and TLI values are higher than 0.90, while RMSEA and SRMR values are lower than 0.08 (see Table 6). We then tested if there is metric invariance, which evaluates if the factor loadings are equivalent for men and women. The difference between CFI and RMSEA of configural and metric invariance was 0.000 and 0.004 respectively, which is less than 0.01 and indicative of metric invariance achievement. We also evaluated scale's scalar invariance, the possibility indicator means to be equivalent for males and females. The difference among CFI and RMSEA of metric and scalar invariance was 0.002 and 0.005 respectively, which is less than 0.01 and means that there is scalar invariance across gender in the scale.

\subsection{Normative Data}

To assist researchers better interpret Stress Mindset Measure's scores, means, standard deviations, ranges and percentiles were computed for scale's factors (see Table 7).

\section{Discussion}

The purpose of the present study was to validate the Greek version of the Stress Mindset Measure (SMM) in order to facilitate the blooming of research and interventions concerning the stress mindset in the Greek population.

The translation and adaptation results show that the six-step methodology followed resulted in a Greek version of the SMM, which depicts the meanings that the creators of the instrument captured in each item. Furthermore, the item analysis findings indicated good content homogeneity for each of the eight SMM items.

Table 6. Factorial invariance across gender for the SMM model.

\begin{tabular}{cccccccc}
\hline & $\mathbf{x}^{2}$ & $\mathbf{d f}$ & $\mathbf{x}^{2} / \mathbf{d f}$ & CFI & TLI & RMSEA & SRMR \\
\hline Configural & $248.803^{* * *}$ & 57 & 4.365 & 0.933 & 0.90 & 0.050 & 0.050 \\
Metric & & & & 0.933 & & 0.046 & \\
Scalar & & & & 0.935 & & 0.041 & \\
\hline
\end{tabular}

Note. ${ }^{* *} p$-value $<0.001, C F I=$ comparative fit index, $T L I=$ Tucker-Lewis index, $R M S E A=$ root mean square error of approximation, $S R M R=$ standardized root mean square residual. Extraction method: maximum likelihood.

Table 7. Normative data for SMM factors $(N=784)$.

\begin{tabular}{ccccccccccc}
\hline & \multirow{2}{*}{ Mean } & \multirow{2}{*}{$S D$} & Range & \multicolumn{1}{c}{ Percentiles } \\
\cline { 5 - 11 } & & & & $\mathbf{5}$ & $\mathbf{1 0}$ & $\mathbf{2 5}$ & $\mathbf{5 0}$ & $\mathbf{7 5}$ & $\mathbf{9 0}$ & $\mathbf{9 5}$ \\
\hline Positive SM & 4.84 & 3.33 & 16 & 0 & 0 & 2 & 5 & 7 & 9 & 11 \\
Negative SM & 12.26 & 3.10 & 16 & 7 & 8 & 10 & 13 & 15 & 16 & 16 \\
\hline
\end{tabular}

Note. $\mathrm{SM}=$ Stress Mindset. 
Furthermore, the results of the present study indicate a different structure of the SMM in the Greek cultural context. More specifically, two factors were identified instead of a single stress mindset factor, that Crum and colleagues (2013) suggested. The factors represent two different mindsets on the effects of stress: either it is enhancing or debilitating (Crum et al., 2013; Casper et al., 2017). In the Greek context, these two mindsets are found to be distinct and not components of a universal stress mindset, as this dichotomy better emphasizes the fact that stress mindset refers to the evaluation of the nature of stress itself as either enhancing or debilitating (Crum et al., 2013). Another explanation of this finding lies on the reversed items used for the stress-is-debilitating factor. Many studies on psychometrics support that the use of both positive and reversed items jeopardize the unidimensionality of the scale because of secondary sources of variance (Herche \& Engelland, 1996. Suárez-Alvarez, Pedrosa, Lozano, García-Cueto, Cuesta, \& Muñiz, 2018).

Moreover, the examination of measurement invariance across gender showed adequate configural, metric and scalar invariance of the instrument. These findings indicate that the Greek Stress Mindset Measure (SMM) measures stress mindset meaningfully and with the same structure, both in the total sample and across women and men.

The findings of the present study showed high convergent, and discriminant validity of the Greek version of the SMM and the results are in agreement with previous research, confirming that stress mindset is meaningfully related to stress-relevant outcomes (health, performance, and well-being) (Crum et al., 2013).

More specifically, the present study found that the enhancing stress mindset is positively correlated with higher levels of resilience, positive emotions and also positive ways of perceiving stress (self-efficacy when confronting stress) and coping with it (e.g. humor and spirituality). Moreover, enhancing stress mindset found negatively correlated to negative experiences, like feeling helpless when confronting with stress, and less effective ways of coping with stress, like expressing negative feelings. These findings are in line with the previous research found that stress-is-enhancing mindset predicted increased life satisfaction, reduced anxiety and depressive symptoms, more optimal neuroendocrine responses, positive affect, reduced bias for negative faces, improved cognitive flexibility, increased desire for social feedback, greater self-control, as well as higher dispositional resources such as optimism, resilience, and mindfulness (e.g., Crum et al., 2013, 2017; Goyer et al., 2018; Park et al., 2017). Furthermore, individuals with enhancing stress mindset tend to approach stressful situations in order to achieve enhancing outcomes, like increased approach motivation in the face of a stressor, which in turn lead to increased engagement and performance (Crum et al., 2013; Casper et al., 2017).

Also, in contrast to enhancing stress mindset, the present study found that stress-is-debilitating mindset is negatively correlated to positive wellbeing outputs (lower levels of satisfaction with life, positive emotions, resilience and 
self-efficacy when confronting stress) and effective coping mechanisms, like using humor. Besides, being characterized by a debilitating stress mindset found positively correlated with psychological symptomatology (high levels of depression, anxiety and stress), negative feelings (perceived helplessness when confronting stress and negative emotions), and ineffective ways of coping with stress, e.g. avoidance, behavioral disengagement, and expression of negative feelings. These findings also fall in line with research suggesting that individuals with a debilitating stress mindset are less likely to approach stressful situations in order to avoid potential negative consequences (e.g., impaired well-being; Crum et al., 2013). However, by consciously trying to avoid stress, individuals with debilitating stress mindset seem to inflate the levels of perceived stress because are thought to stress about potentially becoming stressed (Crum et al., 2013). In addition, individuals with a weaker stress-is-enhancing mindset found to be more stressed and reported negative emotions (Kilby \& Sherman, 2016).

\section{Conclusion}

In conclusion, the results of the present study support the general proposition that stress mindset influences the extent to which stress is psychologically experienced and behaviorally approached, determining psychological symptoms and performance in the midst of stress (Crum et al., 2013).

The Greek version of the Stress Mindset Measure (SMM) can be used, by researchers and mental health professionals, as a reliable and valid instrument for the measurement of the stress mindset in the Greek population.

\section{Limitations}

A point of concern about the results of the present study relates to the fact that three subscales of the Brief-COPE inventory (humor, avoidance, and expression of negative feelings), demonstrated inadequate internal consistency levels and their results should be interpreted with caution. It is possible that the items included in these subscales do not measure a great variance of the constructs or the constructs are not very compact and needs further clarification. Additionally, the results of the present study do not provide information about the test-retest reliability and the predictive validity of the Stress Mindset Measure (SMM).

\section{Recommendations for Future Research}

Concerning the psychometric characteristics of Stress Mindset Measure (SMM), future research should focus on testing its predictive validity and its sensitivity to change after a psychological, psychoeducational or psychotherapeutic intervention. Moreover, test-retest reliability and the stability of its results over longer periods of time should be further tested.

\section{Conflicts of Interest}

The authors declare no conflicts of interest regarding the publication of this paper. 


\section{References}

Andreou, E., Alexopoulos, E., Lionis, C., Varvogli, L., Gnardellis, C., Chrousos, G. et al. (2011). Perceived Stress Scale: Reliability and Validity Study in Greece. International Journal of Environmental Research and Public Health, 8, 3287-3298. https://doi.org/10.3390/ijerph8083287

Bentler, P. M. (1990). Comparative Fit Indexes in Structural Models. Psychological Bulletin, 107, 238-246. https://doi.org/10.1037/0033-2909.107.2.238

Byrne, B. M. (2013). Structural Equation Modeling with AMOS: Basic Concepts, Applications, and Programming. New York: Routledge. https://doi.org/10.4324/9781410600219

Carver, C. S. (1997). You Want to Measure Coping But Your Protocol's Too Long: Consider the Brief COPE. International Journal of Behavioral Medicine, 4, 92-100. https://doi.org/10.1207/s15327558ijbm0401 6

Casper, A., Sonnentag, S., \& Tremmel, S. (2017). Mindset Matters: The Role of Employees' Stress Mindset for Day-Specific Reactions to Workload Anticipation. European Journal of Work and Organizational Psychology, 26, 798-819. https://doi.org/10.1080/1359432X.2017.1374947

Cohen, S., Kamarck, T., \& Mermelstein, R. (1983). A Global Measure of Perceived Stress. Journal of Health and Social Behavior, 24, 385-396. https://doi.org/10.2307/2136404

Crum, A. J., Akinola, M., Martin, A., \& Fath, S. (2017). The Role of Stress Mindset in Shaping Cognitive, Emotional, and Physiological Responses to Challenging and Threatening Stress. Anxiety, Stress and Coping, 30, 379-395. https://doi.org/10.1080/10615806.2016.1275585

Crum, A. J., Salovey, P., \& Achor, S. (2013). Rethinking Stress: The Role of Mindsets in Determining the Stress Response. Journal of Personality and Social Psychology, 104, 716. https://doi.org/10.1037/a0031201

DeVellis, R. F. (2012). Scale Development: Theory and Applications. Los Angeles, CA: Sage.

Diener, E., Emmons, R. A., Larsen, R. J., \& Griffin, S. (1985). The Satisfaction with Life Scale. Journal of Personality Assessment, 49, 71-75.

https://doi.org/10.1207/s15327752jpa4901 13

Diener, E., Wirtz, D., Tov, W., Kim-Prieto, C., Choi, D. W., Oishi, S. et al. (2010). New Well-Being Measures: Short Scales to Assess Flourishing and Positive and Negative Feelings. Social Indicators Research, 97, 143-156.

https://doi.org/10.1007/s11205-009-9493-y

Galanakis, M., Lakioti, A., Pezirkianidis, C., Karakasidou, E., \& Stalikas, A. (2017). Reliability and Validity of the Satisfaction with Life Scale (SWLS) in a Greek Sample. International Journal of Humanities and Social Studies, 5, 120-127.

Goyer, J. P., Akinola, M., Grunberg, R., \& Crum, A. J. (2018). Evaluation of a Stress Mindset Intervention to Improve Performance and Wellbeing in Underrepresented Minority College Students at a Selective Institution.

Herche, J., \& Engelland, B. (1996). Reversed-Polarity Items and Scale Unidimensionality. Journal of the Academy of Marketing Science, 24, 366. https://doi.org/10.1177/0092070396244007

Hu, L. T., \& Bentler, P. M. (1995). Evaluating Model Fit. In R. H. Hoyle (Ed.), Structural Equation Modeling: Concepts, Issues and Applications (pp. 77-99). Thousand Oaks, CA: Sage.

Hu, L. T., \& Bentler, P. M. (1999). Cut-Off Criteria for Fit Indexes in Covariance Struc- 
ture Analysis: Conventional Criteria versus New Alternatives. Structural Equation Modeling, 6, 1-55. https://doi.org/10.1080/10705519909540118

Hubley, A. (2014). Discriminant Validity. In A. C. Michalos (Ed.), Encyclopedia of Quality of Life and Well-Being Research (pp. 1664-1667). Dordrecht: Springer. https://doi.org/10.1007/978-94-007-0753-5 751

Jamieson, J. P., Mendes, W. B., \& Nock, M. K. (2013). Improving Acute Stress Responses: The Power of Reappraisal. Current Directions in Psychological Science, 22, 51-56. https://doi.org/10.1177/0963721412461500

Jamieson, J. P., Mendes, W. B., Blackstock, E., \& Schmader, T. (2010). Turning the Knots in Your Stomach into Bows: Reappraising Arousal Improves Performance on the GRE. Journal of Experimental Social Psychology, 46, 208-212. https://doi.org/10.1016/j.jesp.2009.08.015

Joreskog, K. G., \& Sorbom, D. (1984). LISREL VI: Analysis of Linear Structural Relationships by the Method of Maximum Likelihood. Mooresville, IN: Scientific Software.

Kapsou, M., Panayiotou, G., Kokkinos, C. M., \& Demetriou, A. G. (2010). Dimensionality of Coping: An Empirical Contribution to the Construct Validation of the Brief-COPE with a Greek-Speaking Sample. Journal of Health Psychology, 15, 215-229. https://doi.org/10.1177/1359105309346516

Keller, A., Litzelman, K., Wisk, L. E., Maddox, T., Cheng, E. R., Creswell, P. D., \& Witt, W. P. (2012). Does the Perception That Stress Affects Health Matter? The Association with Health and Mortality. Health Psychology, 31, 677-684.

https://doi.org/10.1037/a0026743

Kilby, C. J., \& Sherman, K. A. (2016). Delineating the Relationship between Stress Mindset and Primary Appraisals: Preliminary Findings. Springerplus, 15, 188-336. https://doi.org/10.1186/s40064-016-1937-7

Kline, R. B. (2010). Principles and Practice of Structural Equation Modeling (3rd ed.). New York: Guilford Press.

Kyriazos, T. (2017). Reliability of Psychometric Instruments. In M. Galanakis, C. Pezirkianidis, \& A. Stalikas (Eds.), Basic Aspects of Psychometrics (pp. 85-121). Athens: Topos.

Kyriazos, T. A., Stalikas, A., Prassa, K., \& Yotsidi, V. (2018b). Can the Depression Anxiety Stress Scales Short Be Shorter? Factor Structure and Measurement Invariance of DASS-21 and DASS-9 in a Greek, Non-Clinical Sample. Psychology, 9, 1095-1127. https://doi.org/10.4236/psych.2018.95069

Kyriazos, T. A., Stalikas, A., Prassa, K., \& Yotsidi, V. (2018c). A 3-Faced Construct Validation and a Bifactor Subjective Well-Being Model Using the Scale of Positive and Negative Experience, Greek Version. Psychology, 9, 1143-1175. https://doi.org/10.4236/psych.2018.95071

Kyriazos, T. A., Stalikas, A., Prassa, K., Galanakis, M., Yotsidi, V., \& Lakioti, A. (2018a). Psychometric Evidence of the Brief Resilience Scale (BRS) and Modeling Distinctiveness of Resilience from Depression and Stress. Psychology, 9, 1828-1857.

https://doi.org/10.4236/psych.2018.97107

Lazarus, R. S., \& Folkman, S. (1984). Stress, Appraisal, and Coping. New York: Springer Pub. Co.

Lovibond, S. H., \& Lovibond, P.F. (1995). The Structure of Negative Emotional States: Comparison of the Depression Anxiety Stress Scales (DASS) with the Beck Depression and Anxiety Inventories. Behavior Research and Therapy, 33, 335-343.

https://doi.org/10.1016/0005-7967(94)00075-U

Nabi, H., Kivimäki, M., Batty, G. D., Shipley, M. J., Britton, A., Brunner, E. J., \& 
Singh-Manoux, A. (2013). Increased Risk of Coronary Heart Disease among Individuals Reporting Adverse Impact of Stress on Their Health: The Whitehall II Prospective Cohort Study. European Heart Journal, 34, 2697-2705.

https://doi.org/10.1093/eurheartj/eht216

Park, D., Yu, A., Metz, S. E., Tsukayama, E., Crum, A. J., \& Duckworth, A. L. (2017). Beliefs about Stress Attenuate the Relation Among Adverse Life Events, Perceived Distress, and Self-Control. Child Development, 62, 1269.

https://doi.org/10.1111/cdev.12946

Pezirkianidis, C., Karakasidou, E., Dimitriadou, D., \& Stalikas, A. (2017). Translation and Adaptation of Psychometric Instruments. In M. Galanakis, C. Pezirkianidis, \& A. Stalikas (Eds.), Basic Aspects of Psychometrics (pp. 489-512). Athens: Topos Publications.

Pezirkianidis, C., Karakasidou, E., Lakioti, A., Stalikas, A., \& Galanakis, M. (2018). Psychometric Properties of the Depression, Anxiety, Stress Scales-21 (DASS-21) in a Greek Sample. Psychology, 9, 2933-2950. https://doi.org/10.4236/psych.2018.915170

Piedmont, R. L. (2014). Inter-Item Correlations. In A. C. Michalos (Ed.), Encyclopedia of Quality of Life and Well-Being Research (pp. 3303-3304). Dordrecht: Springer. https://doi.org/10.1007/978-94-007-0753-5 1493

Podsakoff, N. P., LePine, J. A., \& LePine, M. A. (2007). Differential Challenge Stressor-Hindrance Stressor Relationships with Job Attitudes, Turnover Intentions, Turnover, and Withdrawal Behavior: A Meta-Analysis. Journal of Applied Psychology, 92, 438-454. https://doi.org/10.1037/0021-9010.92.2.438

Schermelleh-Engel, K., Moosbrugger, H., \& Müller, H. (2003). Evaluating the Fit of Structural Equation Models: Tests of Significance and Descriptive Goodness-of-Fit Measures. Methods of Psychological Research Online, 8, 23-74.

Schreiber, J. B., Nora, A., Stage, F. K., Barlow, E. A., \& King, J. (2006). Reporting Structural Equation Modeling and Confirmatory Factor Analysis Results: A Review. The Journal of Educational Research, 99, 323-338. https://doi.org/10.3200/JOER.99.6.323-338

Smith, B. W., Dalen, J., Wiggins, K., Tooley, E., Christopher, P., \& Bernard, J. (2008). The Brief Resilience Scale: Assessing the Ability to Bounce Back. International Journal of Behavioral Medicine, 15, 194-200. https://doi.org/10.1080/10705500802222972

Suárez-Alvarez, J., Pedrosa, I., Lozano, L. M., García-Cueto, E., Cuesta, M., \& Muñiz, J. (2018). Using Reversed Items in Likert Scales: A Questionable Practice. Psicotema, 30, 149-158.

Tucker, L. R., \& Lewis, C. (1973). A Reliability Coefficient for Maximum Likelihood Factor Analysis. Psychometrika, 38, 1-10. https://doi.org/10.1007/BF02291170

Updegraff, J. A., \& Taylor, S. E. (2000). From Vulnerability to Growth: Positive and Negative Effects of Stressful Life Events. In J. Harvey, \& E. Miller (Eds.). Loss and Trauma: General and Close Relationship Perspectives (pp. 3-28). Philadelphia, PA: Brunner-Routledge.

Yusoff, M. S. B. (2013). Psychometric Properties of the Depression Anxiety Stress Scale in a Sample of Medical Degree Applicants. International Medical Journal, 20, 295-300. 